\title{
Towards a new technological solution for Community Energy Storage
}

\author{
Diogo Varajão, Luís M. Miranda, Rui E. Araújo \\ INESC TEC, Faculdade de Engenharia da Universidade do Porto \\ Campus da FEUP, Rua Dr. Roberto Frias, 4200-465 Porto, PORTUGAL \\ E-Mail: diogo.varajao@fe.up.pt, luis.m.miranda@inescporto.pt,raraujo@fe.up.pt
}

\section{Acknowledgements}

This work is partially funded by National Funds through FCT - Science and Technology Foundation, through the scholarship SFRH/BD/89327/2012, and in part by Project NORTE-07-0124-FEDER-000056 financed by the North Portugal Regional Operational Programme (ON.2 - O Novo Norte), under the National Strategic Reference Framework (NSRF), and through the European Regional Development Fund (ERDF), and by FCT. The authors would like to thank Dr. Manuel Barragan for their valuable contributions and discussions about the VSC.

\section{Keywords}

Energy storage, Matrix converter, Distribution of electrical energy, Power quality, Silicon Carbide (SiC)

\begin{abstract}
Energy storage in low voltage grid is receiving increased attention due to renewables integration and consumption growth, challenges faced nowadays by grid operators. In this work, a study of main implementation issues for community energy storage (CES) is presented along with a comparison between possible solutions for the bidirectional isolated power conversion system (PCS) to interface a battery pack with the electric power grid. The aim of this research is to increase the power density of the power converter and keeping simultaneously the same reliability of traditional solutions. These goals are pursued to be achieved through the reduction of the conversion stages and utilization of new optimization methodologies to reduce the volume of the passive components. The proposed topology for the PCS is based on a matrix converter (MC) that performs a direct $\mathrm{AC}$ to $\mathrm{AC}$ conversion between the grid and a high-frequency transformer (HFT). With this solution it is possible to eliminate the traditional DC-link capacitor and obtain a single-stage power conversion with bidirectional power flow capability. This proposed solution is evaluated and compared with a conventional two-stage topology through extensive simulation. Two prototypes systems were designed for a $10 \mathrm{~kW}$ PCS to connect the three-phase $230 / 400 \mathrm{Vrms}, 50 \mathrm{~Hz}$ mains to a battery pack with voltage range of $320 \mathrm{~V}$ to $490 \mathrm{~V}$. Simulation results are presented to assess the power quality provided by the front-end and the battery side converters, as well as performance evaluation and efficiency analysis.
\end{abstract}

\section{Introduction}

Over the last four years, energy storage systems have become an even more active research area. Increasing concerns over higher penetration of renewable energy sources (RES) along with the integration of electric vehicles into the low voltage grid is creating a need for a more flexible and reliable grid operation [1]. The recent IEA outlook [2] projects that world electricity demand increases more than two-thirds over the period 2011-2035, and nearly half of the net increase in electricity generation comes from renewables. In this way, the share of renewables rises from $20 \%$ in 2011 to $31 \%$ in 2035 [2]. In addition to the increasing electricity demand, the escalate of oil prices, the aging of the grid infrastructure, and the need to reduce $\mathrm{CO}_{2}$ emissions, offer new challenges in power balancing [3]. Energy storage is seen as a solution since it can be used to mitigate the intermittency of RES, reduce the need for grid reinforcement and expansion, and supply more flexibility and security to the grid [4-7].

An energy storage system can be split in two main modules: the energy storage element and the power conversion block. For this work, the store of energy is assumed be based on batteries, since it seems to be the more promising technology for low voltage grid applications [7, 8]. The power conversion block consists in a bidirectional power conversion system (PCS) to interface the batteries with the electric power grid. Several solutions were been proposed for the PCS [9-12]. The first one is a classical solution, implemented with a three-phase voltage source converter (VSC) [13] and a buck-boost DC-DC converter to regulate the voltage and current in the batteries. The galvanic isolation between the grid and the battery pack is provided by a low-frequency transformer (LFT). This solution has the advantages of a low complexity due to reduced number of components, well-known control and design techniques, and wide 
availability of integrated components. However, the use of a low-frequency transformer is not suitable to obtain a high-power density conversion system. An alternative is to employ a high-frequency transformer (HFT) in the DC-DC conversion stage in order to significantly reduce the size and volume of the transformer. Possible topologies for the high-frequency isolated DC-DC converter are Dual Half-Bridge (DHB), Dual Active-Bridge (DAB) or resonant DC-DC converters. Nevertheless, the needed of a DC-bus to decouple the operation of the three-phase VSC from the DC-DC converter is also a limitation in terms of volume and shorter life of the capacitors.

Several single-stage power converters were proposed to perform bidirectional AC-DC power conversion as a possible alternative for the traditional two-stage solutions. For instance, three-phase AC-DC converters could be based on multi-port approach [14], AC-DC DAB configuration [15-17] or even exploring the high-frequency link (HFL) concept [18-21]. The use of a matrix converter (MC) for the front-end is an interesting solution due to the capability to perform a direct $\mathrm{AC}$ to $\mathrm{AC}$ conversion without a DC-link [22].

In this work is made and extensive comparison between the three-phase single-stage isolated and bidirectional AC-DC converter based on a matrix converter (HFLMC), and the traditional solution based on a Voltage Source Converter and a Dual Active-Bridge (VSC-DAB). Two prototype systems were designed for a $10 \mathrm{~kW}$ PCS to connect the three-phase $230 / 400 \mathrm{Vrms}, 50 \mathrm{~Hz}$ mains to a battery pack with voltage range of $320 \mathrm{~V}$ to $490 \mathrm{~V}$. Simulation results are presented to assess the power quality provided by the front-end and the battery side converters, as well as performance evaluation, efficiency analysis and discussion of most relevant design components.

\section{Community Energy Storage}

Since electrical energy cannot be stored in bulk, it needs to be converted into a different form for storage [4]. Presently, almost $99 \%$ of worldwide storage capacity is provided by large-scale pumped hydro storage systems (PHS) [7]. The original intent of these plants was to provide demand levelling but now they are used to provide ancillary services, such as frequency regulation [1]. Another technology for bulk storage is compressed air energy storage (CAES). By compressing air during off-peak periods allows simultaneously increase the efficiency of gas turbines and produce electricity during peak periods $[1,5]$. Although, since PHS and CAES are located far away from load centers, they can do little to handle congestion issues that affect transmission and distribution networks [1].

In future, intermittent generation will provide the majority of energy, what will create a need for more storage, flexibility and dynamics in the grid [5]. This way, it is important to distinguish "energy storage" from "power storage". The "energy storage" has time shifting capability and is used to leveling the load diagram. The "power storage" is focused on speed of response, and is used for frequency regulation and to provide spinning reserve [1]. It was stated in [23] that fast response (4 second to achieve full power) is worth twice as much as slower response (20-min ramp-up for generation assets) [1]. Batteries and flywheels have very fast response and can affect frequency control with less energy compared with fossil fuel plants [1], since the interface is implemented using power electronic converters. The dynamic reaction of "power storage" is more important than long term capacity of "energy storage" [5].

Due to its energy density, batteries have high potential to provide energy storage, as also providing several power storage services [5, 7]. Battery storage can be fitted to high power or energy applications, and range from $2 \mathrm{~kW}(5 \mathrm{kWh}-20 \mathrm{kWh})$ up to $50 \mathrm{MW}$ (MWh scale) [7]. With availability of more advanced batteries, utilities are deploying more distributed batteries (several MW) at the substation level for peak load management and reliability improvement [1]. These storage systems can defer upgrades of substations for two to three years to accommodate short-term localized growth [4].

The energy storage needs to follow the generation move towards the new paradigm based on distributed energy resources (DER). Locating storage near loads and distributed generation (DG) opens up opportunities to use storage for more applications than the bulk storage [24]. Inserting energy storage in low voltage grid, and near the prosumers, increases the global value of the solution [25]. Due to proximity with costumers, this system is commonly named community energy storage (CES) [8]. Fig. 1 shows the community energy storage concept. Batteries are the most promising technology for these systems, enabling energy and power capabilities [7]. The centralized operation of several CES units can provide the same benefits of a MW scale battery [25]. Furthermore, the aggregation of CES units through advanced metering infrastructure (AMI), enable grid operator to enter the electricity market [4]. Economic value of the storage is directly related to the difference between on-peak and off-peak prices $[4,26]$. The CES offers a range of ancillary services for the grid operator, allowing increase of flexibility and reliability in the grid operation $[1,7,24]$. Moreover, if advanced services are added this storage solution could become more beneficial and largely adopted. 


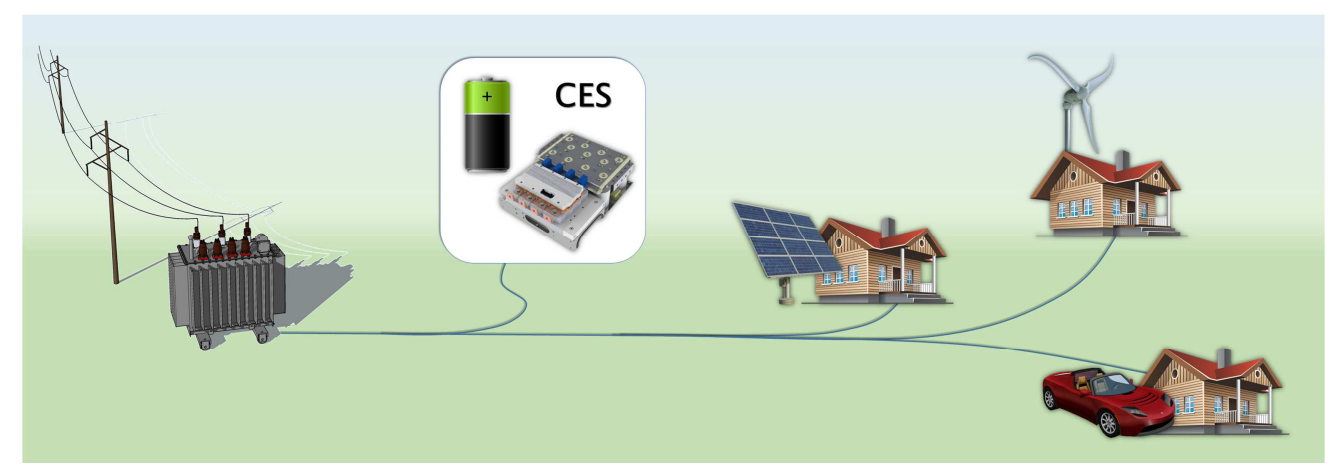

Fig. 1: Integration of the community energy storage unit inside low voltage distribution grid.

\subsection{Functionalities and benefits of CES}

CES can operate as an energy source in a daily cycle, using a significant part of the stored energy. CES can store energy in periods of low demand, and release it at high demand periods, implementing peak shaving and peak shifting. Shaving reduces peak demand and allows offsetting a growing cost for generating extra power to meet very short period of demand [3, 8, 27]. Peak shifting stores the energy produced by photovoltaic and supplies it in peak load period. By shifting the total load from peak to the base, CES help the grid operator to reduce the maximum currents flowing from the transmission and distribution. This allows grid operator to defer investment into upgrading their network capacity, being this one of the richest opportunities for distributed storage [24]. Moreover, since the CES is located close to the loads, energy exchange with customers is more efficient [1]. Then, power losses during transmission are greatly reduced [26]. Therefore, the effectiveness of energy storage operation with CES is much higher than other methods [8].

CES can also be a solution to unpredictably of renewables generation [8]. This system can buffer and smooth RES intermittency by absorbing and delivering power [28]. When the consumption in one area is lower than generation, a reverse power flow occurs to MV. This can rise voltage above the limits, principally in rural grids due to longer cables and overload equipment [27]. Presence of CES in these grids can store the excess of energy and avoid reverse power flow. Therefore, the hosting capacity of the distribution grids is increased allowing the integration of even more distributed power generation [29].

In terms of power storage, the CES can operate as a power source using the maximum available power rating with a faster response. This takes place for short periods and uses a small energy amount. CES can be used to maintain the voltage within a limit range, providing voltage support [27]. Lower voltages can be provoked by loss of microgeneration or appearance of heavy loads like electric vehicle battery chargers [30]. In island operation, frequency may also be affected and should therefore be regulated. Due to its high ramp-up response, the CES can locally provide a power boost to compensate the unbalances and regulate the frequency [31]. As a result of costumer proximity, CES can also act as an uninterruptible power supply (UPS) to feed the loads until the power be restored $[32,33]$. In this way, CES allow for increased power safety and reliability in weak grids [24].

\section{Requirements and Features for the PCS}

Within the CES, some constraints should be addressed to implement an effective solution for the market. Regarding the power conversion system, reliability and maintenance issues are critical, since these systems are to be installed in remote locations, especially outdoor or in distribution transformer rooms. These requirements can be fulfilled avoiding components which performance depends on environmental conditions and running time. Currently, the two main components of a PCS with such problems are electrolytic capacitors and active cooling systems.

A minimum power quality should be ensured at grid and battery interfaces. In the grid interface, the power quality requirements are defined on international standards, such as IEEE 519 or IEC 61000-32. Particularly, according [34] storage units must always generate symmetrical, three-phase rotary currents. For the batteries interface, the requirements come from the battery supplier. Waveforms with low ripple and low harmonic content are always desirable for capacitors and inductors operate with low temperatures, which results in a longer operating life.

Safety is a major concern for equipment installed close to residential areas. If the voltage level for the batteries is under 50 volts it is widely accepted that the human safety is ensured, and the work performed may usually be considered to be de-energized work [35]. Therefore, installation and maintenance are benefited with this voltage level, because they can be made easily in energized circuits. If the system is galvanically isolated and double-grounded there is no risk of exposure to dangerous potentials. To provide galvanic isolation, prevent dc current injection to the grid and perform voltage level adaptation, a 
power transformer should be employed. A low frequency transformer is a major penalty for weight and volume. Thus, a demand for high-frequency isolation techniques should be made if low weight and volume are pursued. A large size and weight will also increase handling and installation cost. For installation in the distribution transformer rooms, a reasonable power density is necessary to ensure that the CES doesn't exceed the available volume. Furthermore, passive cooling represents typically a significant part of the volume and also the weight of the converter, which make this cooling technique reasonable only for converters with low losses. For that, operation with higher temperatures can be done using the emerging high temperature silicon carbide MOSFETs [36].

\subsection{Standards}

Storage systems must meet applicable grid interconnection requirements. IEEE 1547 is the most relevant existing standard applicable to interconnected energy storage systems [37]. It is a result of a recent effort by IEEE SCC21 committee to develop an interconnection standard for all distributed resources [38]. The interconnection requirements related to synchronization, power quality (harmonics, de injection, etc.) and unintentional islanding are specified in this standard. Alternative approaches for intentional islanding operation were further defined in IEEE 1547.4. In order to CES act as a UPS, the operation in island mode is required to continuously supply the load demand and absorb energy from local distributed generation. Anyway, in the close future, the operation in island mode may be not allowed by the specific countries legislation. Therefore, CES should include automatic anti-island device as currently exist in PV systems, specified in standards as VDE 0126-1-1, IEC 61727 or IEEE 1547. Other disconnection requirements in case of frequency or voltage deviation are also specified in these standards.

Recently, the technical requirements for the connection of generators to the LV distribution network were updated in Germany, through the application guide VDE-AR-N 4105. Generators feeding into lowvoltage distribution network have to be involved in maintaining static voltage stability by providing reactive power; they also need to keep connected during frequency deviations, in order to guarantee the stability of the power system [39]. VDE application rule describes requirements for frequency dependent active power control, that solve the so called "50.2 Hz problem" [27]. CES design should take this in account and leverage their potential to assistance the grid operator to guarantee safety and reliability to the power system [34]. The International Electrotechnical Commission (IEC) considers that the energy storage is a major element of Smart Grid. Following this conviction, IEC created the TC-120 committee - Electrical Energy Storage (EES) Systems - to develop the necessary efforts to the standardization in the field of grid EES systems, but this process is only at the beginning.

\section{Power Conversion System for CES}

As previously described, the power conversion system is a key part of the CES. In this section will be described and compared two possible solutions using extensive simulations.

The first topology is one of the traditional solutions for the PCS. The power circuit comprises a threephase voltage source converter connected to the grid with an LCL filter (Fig. 2). Voltage adaptation and galvanic isolation are provided by a high-frequency transformer in the dual active-bridge converter. The $\mathrm{DAB}$ is used to regulate the voltage and current in the battery pack. Hereafter this topology will be called by VSC-DAB. The VSC is controlled to keep a constant voltage in the DC-link using the Space Vector Modulation (SVM). In other hand, the DAB is controlled by conventional Phase-shift Modulation (PSM) [40]. Active power flow from primary bridge to secondary bridge over one switching period is given by:

$$
P_{D A B}=\frac{V_{p} V_{s}}{\omega_{s} L} n \phi\left(1-\frac{|\phi|}{\pi}\right)
$$

where $\omega_{s}$ is the switching frequency in radians per second, $L$ is the primary-referred leakage inductance, $n$ is the transformer turns ratio, and $\phi$ is the phase-shift between square voltages $V_{p}$ and $V_{s}$.



Fig. 2: Conventional topology for PCS based on a voltage source converter and a dual active-bridge (VSC-DAB). 
The proposed technological solution for the PCS uses a $3 \times 2$ matrix converter to make a direct power conversion between the AC grid (low-frequency) and a high-frequency transformer (Fig. 3). With this converter it is possible to eliminate the traditional DC-link capacitor and obtain a single-stage power conversion with bidirectional power flow capability and higher power density. Hereafter this topology will be called by HFLMC. The main drawbacks of the matrix converter are the lack of an intrinsic freewheeling path and the doubled number of switches. Although, comparing the HFLMC topology with the VSC-DAB topology only more two transistors are necessary. Yet, many advantages can be referred, being the first the absence of a DC capacitor bank, which is a key enabler for long life and reliability. A pre-charge circuit for the capacitor bank and for the transformer inrush currents it's unnecessary, because there is no uncontrolled current path between the grid and the primary winding of the high-frequency transformer. Furthermore, only one floating supply is needed to drive both switches of each cell, in a common source configuration. The HFLMC is controlled by a new modulation developed by the authors. Due to space limitation, this new modulation is not presented here but will be published in a future paper. The active power flow from the matrix converter to the full-bridge over one switching period is given by:

$$
P_{H F L M C}=\frac{3}{4} \frac{V_{p} V_{s}}{\omega_{s} L} n \phi\left(1-\frac{|\phi|}{\pi}\right)
$$

where $\omega_{s}$ is the switching frequency in radians per second, $L$ is the primary-referred leakage inductance, $n$ is the transformer turns ratio, and $\phi$ is the phase-shift between voltages $V_{p}$ and $V_{s}$.

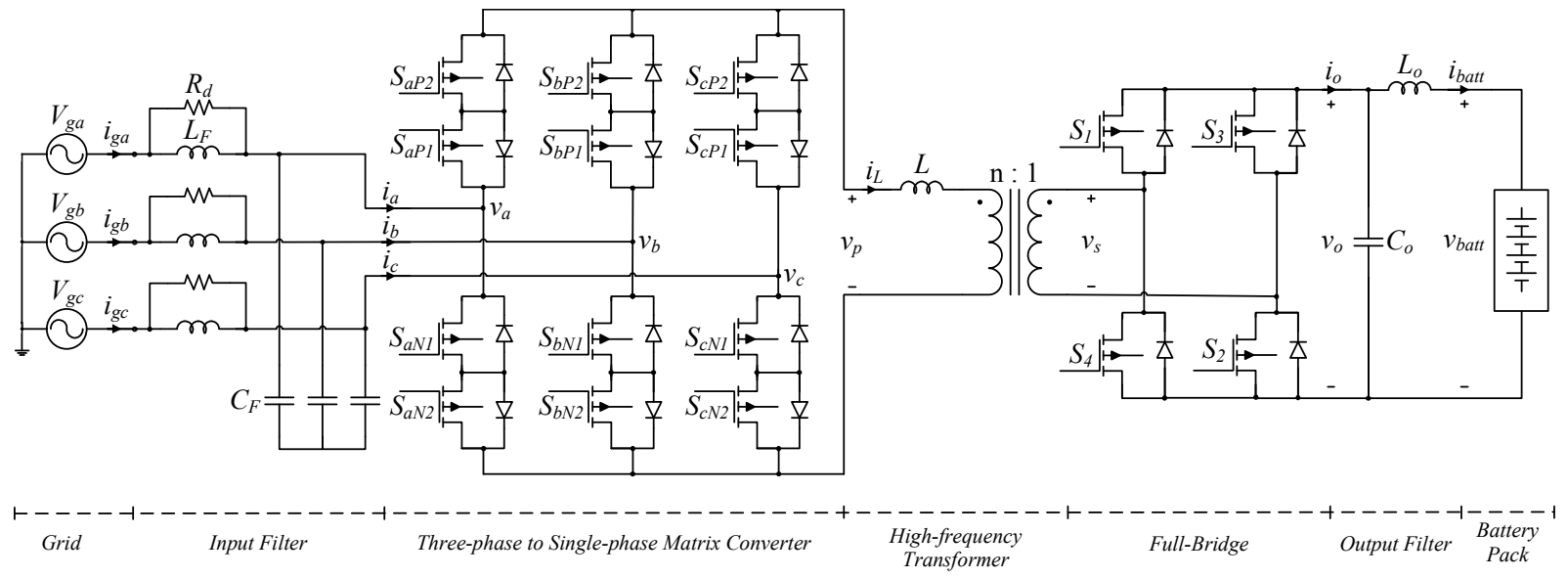

Fig. 3: Proposed topology for the PCS based on $3 \times 2$ matrix converter with a high-frequency link (HFLMC).

Table I shows the comparison of both topologies in terms of component count. Besides the DC-link capacitor, the VSC-DAB topology also needs more magnetic cores due to the use of an LCL filter instead of the LC filter used in the HFLMC. On the other hand, the HFLMC needs more two active switches and the respective drivers.

Table I. Comparison of component count for the two topologies.

\begin{tabular}{|c||c|c|c|c|c|c|c|}
\hline Topology & Switches & Diode & Capacitor & Magnetic Core & Winding & Driver & Isolated sources \\
\hline \hline VSC-DAB & 14 & 14 & 5 & 8 & 9 & 14 & 10 \\
\hline HFLMC & 16 & 16 & 4 & 5 & 6 & 16 & 9 \\
\hline
\end{tabular}

\subsection{Prototypes description}

In order to compare the topologies described above, two prototypes were designed to fulfill the specifications and requirements of Table II. A $10 \mathrm{~kW}$ PCS to connect the three-phase 230/400Vrms, $50 \mathrm{~Hz}$ mains to a battery pack with voltage range of $320 \mathrm{~V}$ to $490 \mathrm{~V}$ is considered. It was decided to investigate the application of silicon-carbide (SiC) MOSFETs for the switching devices. More specifically, the $1.2 \mathrm{kV}$ MOSFETS of type C2M0025120D with a typically on-resistance of $25 \mathrm{~m} \Omega$ at a junction temperature of $25^{\circ} \mathrm{C}$ were chosen [41]. The components for the VSC-DAB and for the HFLMC prototypes are listed in Table III and Table IV, respectively.

Table II. Specifications and requirements of the three-phase power conversion system.

\begin{tabular}{|l|l||l|l|}
\hline Line-to-line voltage $\left(V_{A C, l, \text { nom }}\right)$ & $3 \times 400 V_{\text {rms }} \pm 10 \%$ & Max. charging current $\left(I_{\text {batt,max }}\right)$ & $31 \mathrm{~A}$ \\
\hline Input frequency $\left(f_{i}\right)$ & $50 \mathrm{~Hz}$ & Battery current ripple $\left(I_{\text {batt ripple }}\right)$ & $\leq 5 \%$ (40 to $\left.100 \% I_{\text {batt,nom }}\right)$ \\
\hline Battery voltage $\left(V_{\text {batt }}\right)$ & $380 \mathrm{~V}(320$ to $490 \mathrm{~V})$ & Power factor $(P F)$ & $>0.9\left(40\right.$ to $\left.100 \% I_{A C, P, n o m}\right)$ \\
\hline Output power $\left(P_{\text {nom }}\right)$ & $\pm 10 \mathrm{~kW}$ & Total Harmonic Distortion $(T H D)$ & $\leq 5 \%\left(40\right.$ to $\left.100 \% I_{A C, P, \text { nom }}\right)$ \\
\hline Switching frequency $\left(f_{s}\right)$ & $20 \mathrm{kHz}$ & Efficiency & $\eta>95 \%\left(50\right.$ to $\left.100 \% P_{\text {nom }}\right)$ \\
\hline AC current $\left(I_{A C, P, \text { nom }}\right)$ & $3 \times 15 \mathrm{~A}_{\mathrm{rms}}$ & \multirow{3}{*}{ Additional requirements } & Bidirectional power flow \\
\cline { 2 - 2 } DC-link - VSC-DAB $\left(V_{D C}\right)$ & $700 \mathrm{~V}$ & & Galvanic isolation \\
\cline { 2 - 3 } & & & Passive cooling \\
\hline Nominal charg. current $\left(I_{\text {batt,nom }}\right)$ & $26 \mathrm{~A}$ & &
\end{tabular}


Table III Components of the VSC-DAB.

\begin{tabular}{|c|c|}
\hline $\begin{array}{l}\text { MOSFETs SaP, } \\
\ldots \mathrm{ScN} ; \mathrm{S} 5, \ldots \mathrm{S} 8\end{array}$ & $\begin{array}{l}\text { 1x C2M0025120D, } 1.2 \mathrm{kV}, 90 \mathrm{~A} \text {, } \\
25 \mathrm{~m} \Omega\end{array}$ \\
\hline $\begin{array}{l}\text { MOSFETs S1, } \\
\text { S2, S3, S4 }\end{array}$ & $\begin{array}{l}\text { 2x C2M0025120D, } 1.2 \mathrm{kV}, 90 \mathrm{~A} \text {, } \\
25 \mathrm{~m} \Omega\end{array}$ \\
\hline Transformer & $\begin{array}{l}\text { 1x PM114/93 N87; } 36 \text { primary } \\
\text { turns, } 18 \text { secondary turns; Litz wire, } \\
30 \text { strands, } 0.400 \mathrm{~mm}\end{array}$ \\
\hline Inductor $L_{f}, L_{B}$ & $\begin{array}{l}\text { 1x PM50/39 N87; } 41 \text { turns; Litz } \\
\text { wire, } 30 \text { strands, } 0.400 \mathrm{~mm}\end{array}$ \\
\hline Inductor $L_{o}$ & 1x SER2918H, $10 \mu \mathrm{H}, 2.60 \mathrm{~m} \Omega$ \\
\hline Capacitors $C_{f}$ & $1 \times$ B32926C3565K, $5.6 \mu \mathrm{F}, 305 \mathrm{~V}$ \\
\hline Capacitor $C_{d c}$ & $\begin{array}{l}\text { 2x2x B43501A0567M000, } 560 \mu \mathrm{F}, \\
420 \mathrm{~V}\end{array}$ \\
\hline Capacitors $C_{o}$ & 4x B32678G6256K, $25 \mu \mathrm{F}, 630 \mathrm{~V}$ \\
\hline $\begin{array}{l}\text { Heat Sink } \\
\text { (passive cooling) }\end{array}$ & $\begin{array}{l}\text { 2x FISCHER ELEKTRONIK - SK } \\
92 / 75 \text { SA } 1.60^{\circ} \mathrm{C} / \mathrm{W}\end{array}$ \\
\hline \multicolumn{2}{|c|}{$\begin{array}{l}\text { Total volume of comp.: } 3.1 \mathrm{~L}(2.5 \mathrm{~L} \text { excluding heat sink }) \\
\text { Total weight of comp.: } 5.9 \mathrm{Kg}(5.1 \mathrm{Kg} \text { excluding heat sink })\end{array}$} \\
\hline
\end{tabular}

Table IV Components of the HFLMC.

\begin{tabular}{|c|c|}
\hline $\begin{array}{l}\text { MOSFETs SaP1, } \\
\ldots \text { ScN2 }\end{array}$ & $\begin{array}{l}1 \mathrm{x} \mathrm{C} 2 \mathrm{M} 0025120 \mathrm{D}, 1.2 \mathrm{kV} 90 \mathrm{~A} \text {, } \\
25 \mathrm{~m} \Omega\end{array}$ \\
\hline $\begin{array}{l}\text { MOSFETs S1, } \\
\text { S2, S3, S4 }\end{array}$ & $\begin{array}{l}2 \mathrm{x} \mathrm{C} 2 \mathrm{M} 0025120 \mathrm{D}, 1.2 \mathrm{kV}, 90 \mathrm{~A} \text {, } \\
25 \mathrm{~m} \Omega\end{array}$ \\
\hline Transformer & $\begin{array}{l}\text { 1x PM87 N87; } 32 \text { primary turns, } \\
16 \text { secondary turns; Litz wire, } 30 \\
\text { strands, } 0.400 \mathrm{~mm}\end{array}$ \\
\hline Inductor $L_{f}$ & $\begin{array}{l}\text { 1x PM50/39 N87; } 52 \text { turns; Litz } \\
\text { wire, } 30 \text { strands, } 0.400 \mathrm{~mm}\end{array}$ \\
\hline Inductor $L_{o}$ & 6x SER2918H, $10 \mu \mathrm{H}, 2.60 \mathrm{~m} \Omega$ \\
\hline Capacitors $C_{f}$ & 2x B32926C3106K, $10 \mu \mathrm{F}, 305 \mathrm{~V}$ \\
\hline Capacitors $C_{o}$ & 4x B32678G6256K, $25 \mu \mathrm{F}, 630 \mathrm{~V}$ \\
\hline $\begin{array}{l}\text { Heat Sink } \\
\text { (passive cooling) }\end{array}$ & $\begin{array}{l}\text { 2x FISCHER ELEKTRONIK - SK } \\
56 / 75 \mathrm{SA} 0.45^{\circ} \mathrm{C} / \mathrm{W}\end{array}$ \\
\hline
\end{tabular}

The input filters for both converters were designed in order to provide the same harmonic attenuation at nominal operating conditions. The LCL filter for the VSC-DAB topology was designed following the procedure described in [42]. The resonant frequency was fixed at $6 \mathrm{kHz}$ with $L_{f}=L_{B}=250 \mu \mathrm{H}, C_{f}=5.6$ $\mu \mathrm{F}$ and a damping resistance $R_{d}=1 \Omega$. The LC filter for the HFLMC topology was designed following the procedure described in [43]. The resonant frequency was fixed at $2 \mathrm{kHz}$ with $L_{f}=320 \mu \mathrm{H}, C_{f}=20 \mu \mathrm{F}$ and a damping resistance $R_{d}=8 \Omega$.

The turns ration $n$ of the transformer and the leakage inductance are designed in order to allow the maximum output power flow in the worst operation conditions. In this way, was selected the pair $n=2$ / $L=250 \mu \mathrm{H}$ for the VSC-DAB, and $n=2 / L=84 \mu \mathrm{H}$ for the HFLMC.

Concerning the connection with the battery pack, an output LC filter was designed to reduce the current ripple, and providing the same attenuation at nominal operating conditions for both converters. For the VSC-DAB $L_{o}=10 \mu \mathrm{H}$ and $C_{o}=100 \mu \mathrm{F}$ were chosen, and for the HFLMC $L_{o}=60 \mu \mathrm{H}$ and $C_{o}=100 \mu \mathrm{F}$. An aluminum electrolytic capacitor of $C_{d c}=560 \mu \mathrm{F}$ was selected for the DC-link of the VSC-DAB. SiC MOSFETs can be operated at higher temperatures, providing simultaneously low conduction and switching losses compared with IGBTs. So, passive cooling method was designed to provide a proper converter operation considering an ambient temperature of $40{ }^{\circ} \mathrm{C}$. As a criterion to project the heat sink, was decided to have the same maximum junction temperature $\left(100^{\circ} \mathrm{C}\right)$ in both converters for nominal operating conditions.

\subsection{Simulation results}

The two converters are simulated using GeckoCIRCUITS [44] coupled with MATLAB/Simulink. The simulation models and parameters are described in section 4.1 - see Fig. 2 and Fig. 3. The grid was modelled with a three-phase AC voltage source in series with a line impedance of $50 \mu \mathrm{H}$ and $50 \mathrm{~m} \Omega$. In other hand, the battery is modelled by a DC voltage source in series with a resistance of $0.5 \Omega$ as an approximation for the battery internal impedance [9]. For these comparative tests, was decided to control the converter to follow a reference of power at the battery pack. A proportional-integral (PI) controller was designed for this task. The operation of both converts at nominal conditions is shown in Fig. 4 and Fig. 5. A transition in the power reference from $P_{\text {batt }}{ }^{*}=0$ to $P_{\text {batt }}{ }^{*}=10 \mathrm{~kW}$ and then to $P_{\text {batt }}{ }^{*}=-10 \mathrm{~kW}$ was performed to evaluate the dynamic operation of the converters. As can be seen in Fig. 4(a) and Fig. 5(a), the power in the battery is properly controlled, and the power in the grid has a slightly difference due to power losses in the conversion process. Fig. 4(b) and Fig. 5(b) show the voltage and current in the battery pack. A change in the battery voltage naturally occurs due to the internal impedance of the battery. As supposed, only a small ripple appears in the battery current. The measured ripple in battery for both converters over the output power range is represented in Fig. 6, and complies with the requirements listed in Table II. The resultant current in the grid has improved dynamic and power quality even during inversion of the power flow, as shown in Fig. 4(c) and Fig. 5(c). The measured THD in grid current over the output power range is depicted in Fig. 7. As specified in the requirements of Table II, the THD is kept below $5 \%$ for input current above $40 \%$ of $I_{A C, P, n o m}$. Regarding the high frequency link operation, it is noticeable a difference in the primary voltages applied to the transformer (Fig. 4(d) and Fig. 5(d)). This clearly shows the single-stage operation of the HFLMC where a low-frequency envelope appears due to the absence of a DC-link between the grid and the transformer. 


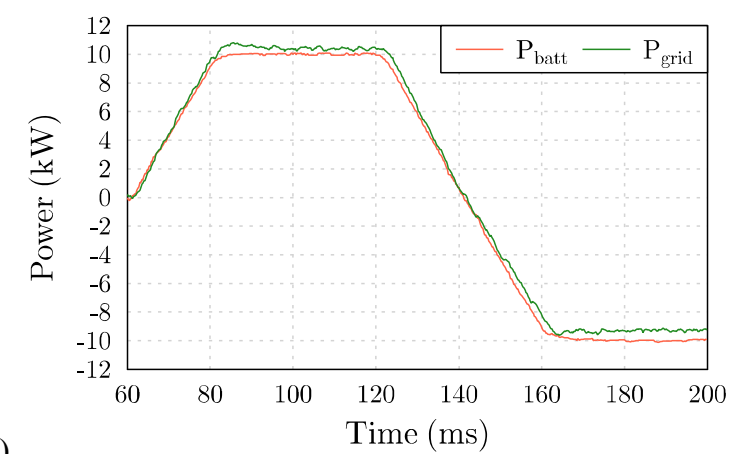

(a)

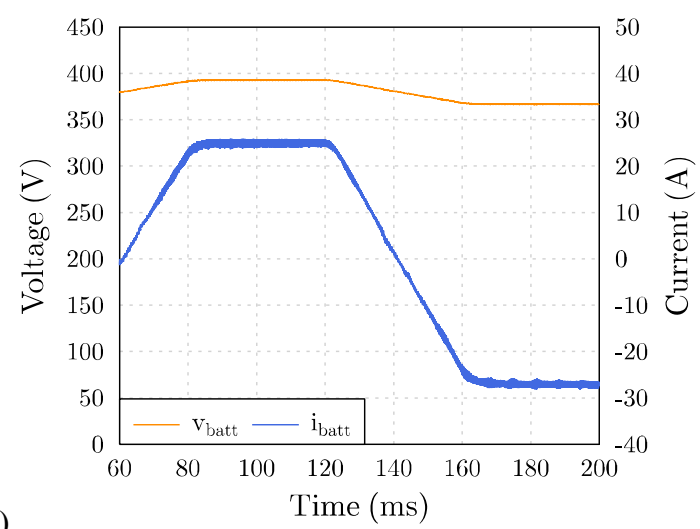

(b)

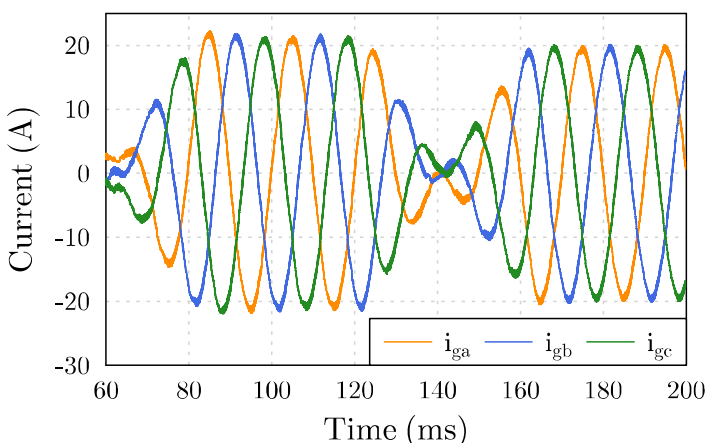

(c)

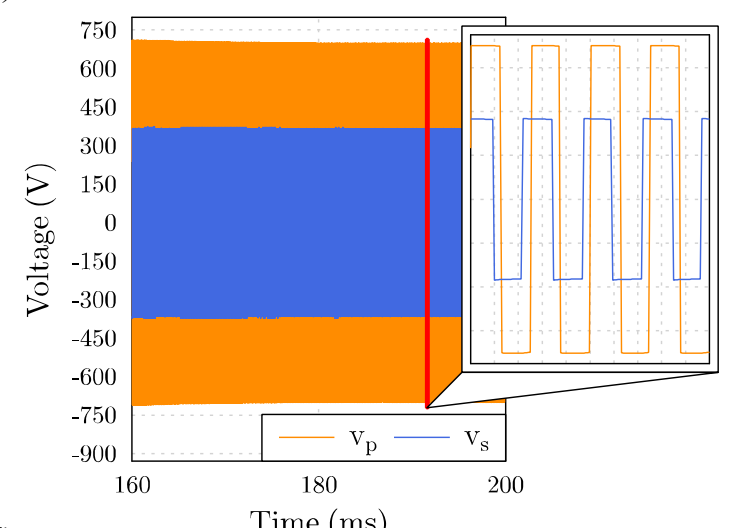

(d)

Fig. 4: Simulation results for the VSC-DAB operation for a transition from $P_{\text {batt }}=0$ to $P_{\text {batt }}{ }^{*}=10 \mathrm{~kW}$ and then to $P_{\text {batt }}{ }^{*}=-10 \mathrm{~kW}$. (a) Simulated power in the battery pack and in the grid, and (b) voltage and current in the battery pack, and (c) AC phase currents $i_{g a}, i_{g b}, i_{g c}$, and (d) voltages $v_{p}, v_{s}$ across the transformer windings.

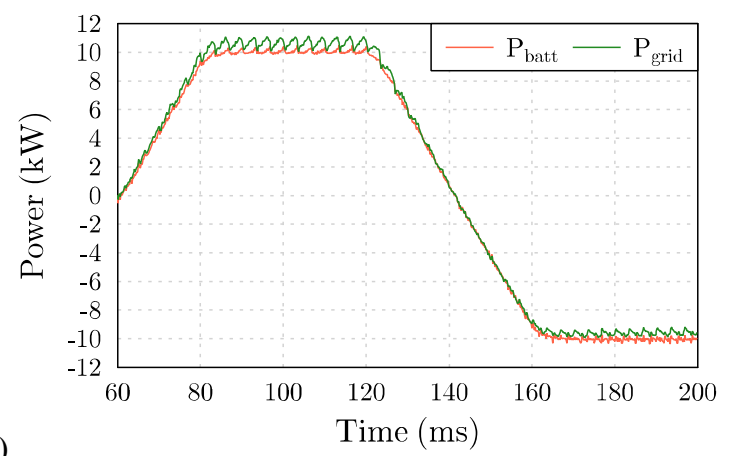

(a)

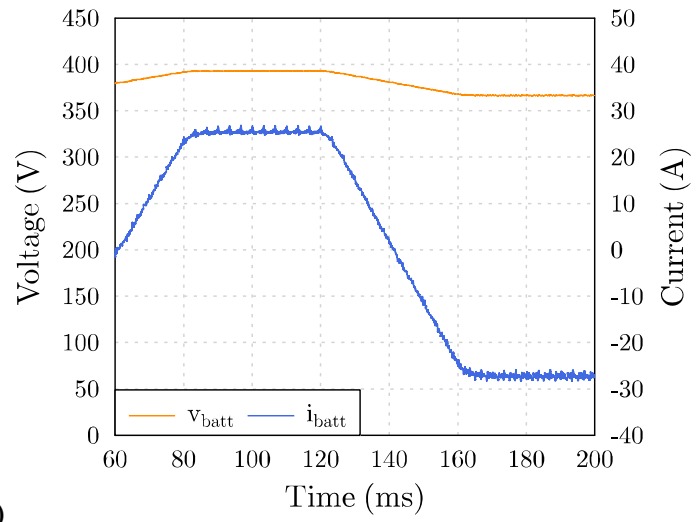

(b)

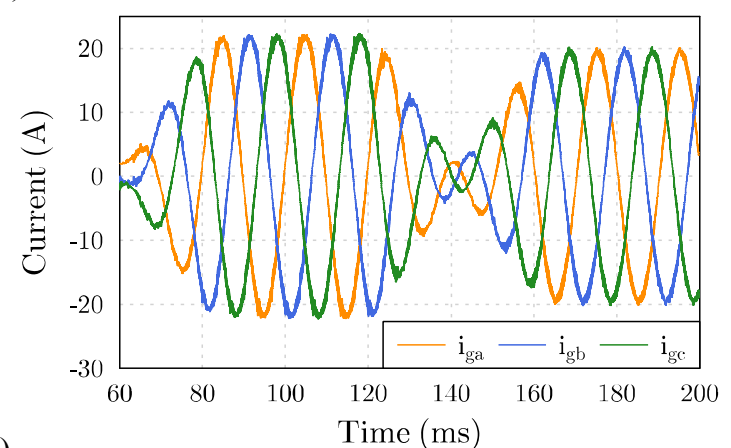

(c)

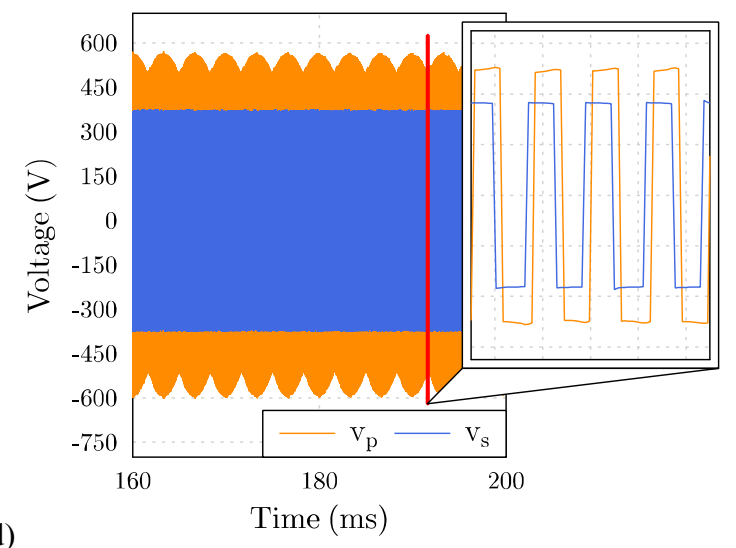

Fig. 5: Simulation results for the HFLMC operation for a transition from $P_{\text {batt }}=0$ to $P_{\text {batt }}{ }^{*}=10 \mathrm{~kW}$ and then to $P_{\text {batt }}{ }^{*}=-10 \mathrm{~kW}$. (a) Simulated power in the battery pack and in the grid, and (b) voltage and current in the battery pack, and (c) AC phase currents $i_{g a}, i_{g b}, i_{g c}$, and (d) voltages $v_{p}, v_{s}$ across the transformer windings.

The measured efficiency over the output power range for battery voltages of $320 \mathrm{~V}$ and $380 \mathrm{~V}$ is plotted in Fig. 8. It can be seen, that the efficiency for the VSC-DAB converter is almost the same for these two output voltages, and reaches a peak of $97.1 \%$ for $8 \mathrm{~kW}$ and a battery voltage of $320 \mathrm{~V}$. 


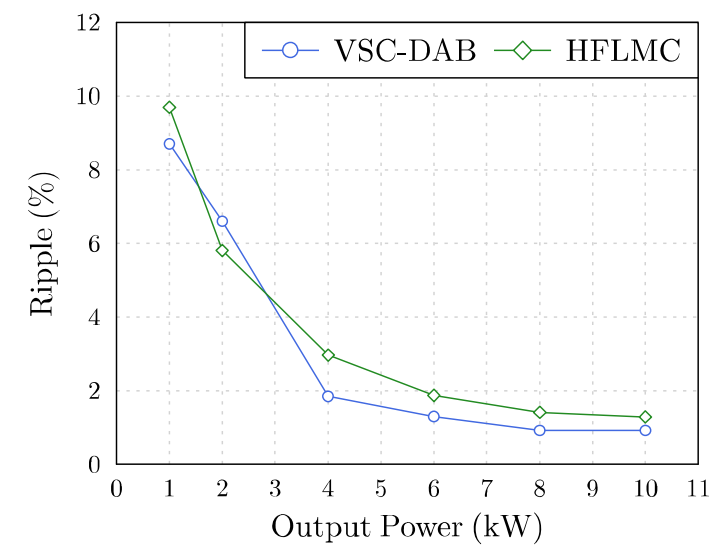

Fig. 6: Measured current ripple in the battery pack for the VSC-DAB and for the HFLMC over the output power range for battery voltage of $380 \mathrm{~V}$.

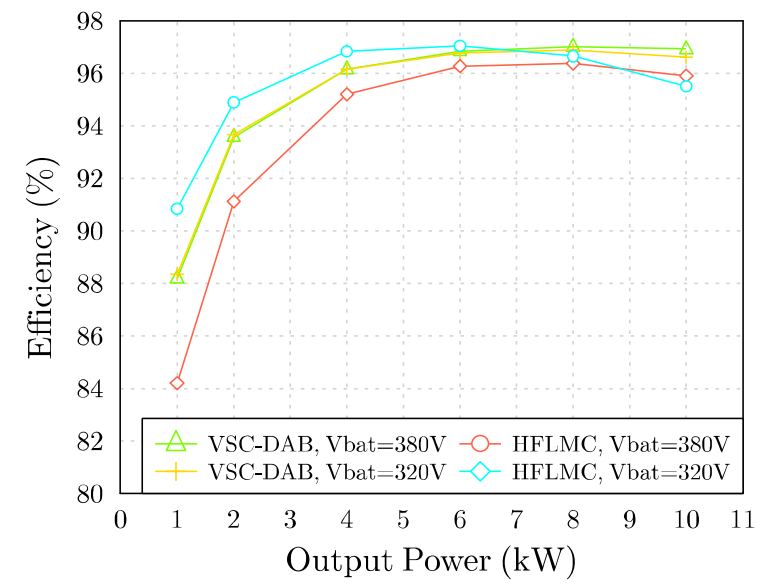

Fig. 8: Measured efficiency in simulation for the Fig. 9: Calculated distribution of the power losses for the VSC-DAB and for the HFLMC over the output HFLMC at an output power of $10 \mathrm{~kW}$ and a battery power range for battery voltages of $320 \mathrm{~V}$ and voltage of $380 \mathrm{~V}$.

$380 \mathrm{~V}$.

For the HFLMC, a peak efficiency of $97.4 \%$ is reached at an output power of $6 \mathrm{~kW}$ and a battery voltage of $320 \mathrm{~V}$. The efficiency curve of the HFLMC for $380 \mathrm{~V}$ is below the other curves, but presents good efficiency near the nominal output power. For the results was considered a load-independent loss component of $20 \mathrm{~W}$, representing auxiliary circuits, gate drives, sensors and EMI filters.

Fig. 9 shows the calculated distribution of the power losses for the HFLMC at nominal operating conditions. It is clear that the SiC MOSFETs account for $62 \%$ of the power losses in the converter. For this reason, a thermal heat sink to ambient resistance of $\mathrm{R}_{\mathrm{th}, \mathrm{s}-\mathrm{a}}=0.22{ }^{\circ} \mathrm{C} / \mathrm{W}$ was selected.

\section{Conclusion}

The need to integrate renewable energy sources and heavy loads such as electric vehicles in the low voltage grid is demanding for new levels of flexibility and reliability. As a relatively new application, the community energy storage can be a key solution for these challenges and an enabling technology for smart grids.

This work analysis the benefits of CES, the main features and requirements imposed by international standards, and discuss the suitability of three alternative topologies. The two ones considering with most interest for this application are designed with realistic components, based on the requirements previously identified, and afterwards modeled for simulation.

A comparative analysis of both topologies operating in closed loop allows to see that the two topologies can track a set point with very small error, in steady-state or during transitions. At the grid interface, smooth and controlled current waveforms can be observed for two critical situations - the converter startup and an inversion in the power flow with full load.

Regarding the power quality at the battery pack, it can be found that with $1 \mathrm{~kW}$ load the current ripple is already below $10 \%$, which stands for a good performance considering most of the application requirements. For higher loads, ripple drops down to around $1 \%$, which indicates that if necessary the 
output filter can be reduced to improve the converter efficiency, reducing cost, weight and size. In this case, for light loads, a variable frequency modulation can be a solution to investigate in order to keep the ripple under a specified limit. Analyzing the harmonic distortion at the grid connection, the values achieved are by far within the most commonly applied standards, with the HFLMC being particularly good in the 10 to $50 \%$ load range, when compared with the VSC-DAB solution. For heavier loads both are very close in terms of THD with values below $4 \%$.

Comparing both topologies in terms of complexity and component count, they are quite similar. It can be noticed that the matrix converter-based topology is by far smaller and lighter, but significantly higher power losses lead to the need for a large heat sink which seriously penalizes this topology. A pie chart with the distribution of the losses allows to see that almost two thirds $(2 / 3)$ of the losses are in the power switches for the HFLMC. They are mainly conduction losses, which have a quadratic relationship with the current value. This phenomenon can be observed in the efficiency plots, where curves for different battery pack voltages are presented. For the tests with a $380 \mathrm{~V}$ battery pack, the shape of the curve is very similar for both topologies. In other hand, for $320 \mathrm{~V}$ tests the efficiency of the HFLMC starts to decrease for load levels above $50 \%$ due to high currents flowing through the power switches. A practical solution for this problem should be the use of multiple switches in parallel. A trade-off must be found between the cost increase in the additional switches and the consequent reduction in costs related to heat dissipation. From these results should be pointed out that the matrix converter has a higher potential for this application, but the efficiency must be improved to result in a compact device. In the next developments, soft-switching will be explored in order to reduce the losses in the power switches. Furthermore, the application of different switching patterns in the modulation to reduce the number of commutations will be also topic for future research. Moreover, the power loss models will be further improved and also the magnetic components will be optimized to obtain a complete design for physical implementation.

\section{References}

[1] B. P. Roberts and C. Sandberg, "The Role of Energy Storage in Development of Smart Grids," Proceedings of the IEEE, vol. 99, pp. 1139-1144, 2011.

[2] IEA, "World Energy Outlook 2013 - Factsheet," International Energy Agency, Nov. 2013.

[3] H. A. H. Hussein et al., "Design considerations for distributed micro-storage systems in residential applications," in Telecommun. Energy Conf. (INTELEC), 32nd Int., 2010, pp. 1-6.

[4] D. Rastler, "New Demand for Energy Storage," Electric Perspectives, vol. 33, pp. 30-47, 2008.

[5] DG ENER, "The future role and challenges of Energy Storage," European Commission, Jan. 2013.

[6] EPIA, "Response to DG ENER Working Paper: "The future role and challenges of Energy Storage"," European Photovoltaic Industry Association, Feb. 2013.

[7] EUROBAT, "Battery Energy Storage for Smart Grids applications," May 2013.

[8] Z. Wei, D. Garrett, J. Butkowski, and W. Yang, "Overview of distributive energy storage systems for residential communities," in Energytech, 2012 IEEE, 2012, pp. 1-6.

[9] B. M. Grainger, G. F. Reed, A. R. Sparacino, and P. T. Lewis, "Power Electronics for Grid-Scale Energy Storage," Proceedings of the IEEE, vol. 102, pp. 1000-1013, 2014.

[10] S. Vazquez et al., "Energy Storage Systems for Transport and Grid Applications," Industrial Electronics, IEEE Transactions on, vol. 57, pp. 3881-3895, 2010.

[11] Q. Hao, Z. Jianhui, L. Jih-Sheng, and Y. Wensong, "A high-efficiency grid-tie battery energy storage system," Power Electronics, IEEE Transactions on, vol. 26, pp. 886-896, 2011.

[12] M. Bragard, N. Soltau, S. Thomas, and R. W. De Doncker, "The Balance of Renewable Sources and User Demands in Grids: Power Electronics for Modular Battery Energy Storage Systems," Power Electronics, IEEE Transactions on, vol. 25, pp. 3049-3056, 2010.

[13] J. M. Maza-Ortega, E. Gomez, A., M. Barragan-Villarejo, E. Romero-Ramos, and A. Marano-Marcolini, "Voltage source converter-based topologies to further integrate renewable energy sources in distribution systems," Renewable Power Generation, IET, vol. 6, pp. 435-445, 2012.

[14] F. Jauch and J. Biela, "Modelling and ZVS control of an isolated three-phase bidirectional AC-DC converter," in Power Electron. and Appl. (EPE), 15th European Conf. on, 2013, pp. 1-11.

[15] N. D. Weise, K. Basu, and N. Mohan, "Advanced modulation strategy for a three-phase AC-DC dual active bridge for V2G," in Vehicle Power and Propuls. Conf. (VPPC), IEEE, 2011, pp. 1-6.

[16] H. S. Krishnamoorthy, P. Garg, and P. N. Enjeti, "A matrix converter-based topology for high power electric vehicle battery charging and V2G application," in IECON 2012 - 38th Ann. Conf. on IEEE Ind. Electron. Soc., 2012, pp. 2866-2871.

[17] M. A. Moonem and H. Krishnaswami, "Analysis of dual active bridge based power electronic transformer as a three-phase inverter," in IECON 2012 - 38th Ann. Conf. on IEEE Ind. Electron. Soc., 2012, pp. 238-243. 
[18] D. Sha, Z. Qin, D. Wu, and X. Liao, "A Digitally Controlled Three-Phase Cycloconverter Type High Frequency AC Link Inverter Using Space Vector Modulation," Journal of Power Electronics (KIPE), vol. 11, pp. 28-36, 2011.

[19] R. Garcia-Gil et al., "A bidirectional and isolated three-phase rectifier with soft-switching operation," Industrial Electronics, IEEE Transactions on, vol. 52, pp. 765-773, 2005.

[20] S. Norrga, S. Meier, and S. Ostlund, "A Three-Phase Soft-Switched Isolated AC/DC Converter Without Auxiliary Circuit," Industry Applications, IEEE Trans. on, vol. 44, pp. 836-844, 2008.

[21] Y. Zhaoyang, J. Minli, Z. Chunjiang, and W. Weiyang, "An Integration SPWM Strategy for High-Frequency Link Matrix Converter With Adaptive Commutation in One Step Based on De-Re-Coupling Idea," Industrial Electronics, IEEE Transactions on, vol. 59, pp. 116-128, 2012.

[22] P. W. Wheeler, J. Rodriguez, J. C. Clare, L. Empringham, and A. Weinstein, "Matrix converters: a technology review," Industrial Electronics, IEEE Transactions on, vol. 49, pp. 276-288, 2002.

[23] Y. V. Makarov, J. Ma, S. Lu, and T. B. Nguyen, "Assessing the Value of Regulation Resources Based on Their Time Response Characteristics," Pacific Northwest National Laboratory, 2008.

[24] J. Eyer and G. Corey, "Energy Storage for the Electricity Grid: Benefits and Market Potential Assessment Guide," Sandia National Laboratories, Feb. 2010.

[25] A. Nourai, R. Sastry, and T. Walker, "A vision \& strategy for deployment of energy storage in electric utilities," in Power and Energy Society General Meeting, 2010 IEEE, 2010, pp. 1-4.

[26] O. HyungSeon, "Optimal Planning to Include Storage Devices in Power Systems," Power Systems, IEEE Transactions on, vol. 26, pp. 1118-1128, 2011.

[27] EPIA, "Connecting the Sun: Solar Photovoltaics on the road to large-scale grid integration," European Photovoltaic Industry Association, September 2012.

[28] L. Xiangjun, H. Dong, and L. Xiaokang, "Battery Energy Storage Station (BESS)-Based Smoothing Control of Photovoltaic (PV) and Wind Power Generation Fluctuations," Sustainable Energy, IEEE Transactions on, vol. 4, pp. 464-473, 2013.

[29] C. A. Hill et al., "Battery Energy Storage for Enabling Integration of Distributed Solar Power Generation," Smart Grid, IEEE Transactions on, vol. 3, pp. 850-857, 2012.

[30] J. A. P. Lopes, F. J. Soares, and P. M. R. Almeida, "Integration of Electric Vehicles in the Electric Power System," Proceedings of the IEEE, vol. 99, pp. 168-183, 2011.

[31] S. N. Laboratories, "DOE/EPRI 2013 Electricity Storage Handbook in Collaboration with NRECA," 2013.

[32] J. M. Guerrero, L. Poh Chiang, L. Tzung-Lin, and M. Chandorkar, "Advanced Control Architectures for Intelligent Microgrids - Part II: Power Quality, Energy Storage, and AC/DC Microgrids," Industrial Electronics, IEEE Transactions on, vol. 60, pp. 1263-1270, 2013.

[33] I. Serban and C. Marinescu, "Control Strategy of Three-Phase Battery Energy Storage Systems for Frequency Support in Microgrids and with Uninterrupted Supply of Local Loads," Power Electronics, IEEE Transactions on, vol. 29, pp. 5010-5020, 2014.

[34] FNN, "Connecting and operating storage units in low voltage networks," Forum Network Technology/Network Operation in the VDE (FNN)August 2013.

[35] J. Cadick, M. Capelli-Schellpfeffer, and D. Neitzel, Electrical Safety Handbook 3E: MGH, 2005.

[36] S. Safari, A. Castellazzi, and P. Wheeler, "Experimental and Analytical Performance Evaluation of SiC Power Devices in the Matrix Converter," Power Electronics, IEEE Transactions on, vol. 29, pp. 2584-2596, 2014.

[37] E. Lemaire et al., "European White Book on Grid-Connected Storage," European Distributed Energy Resources Laboratories, Dec. 2011.

[38] R. C. Dugan, T. S. Key, and G. J. Ball, "Distributed resources standards," Industry Applications Magazine, IEEE, vol. 12, pp. 27-34, 2006.

[39] FNN, "Generators in the low voltage distribution network - INFO about VDE-AR-N 4105," Forum Network Technology/Network Operation in the VDE (FNN), Sept. 2011.

[40] M. N. Kheraluwala et al., "Performance characterization of a high-power dual active bridge," Industry Applications, IEEE Transactions on, vol. 28, pp. 1294-1301, 1992.

[41] Cree. C2M0025120D. Available: http://www.cree.com

[42] M. Liserre, F. Blaabjerg, and S. Hansen, "Design and control of an LCL-filter-based three-phase active rectifier," Industry Applications, IEEE Transactions on, vol. 41, pp. 1281-1291, 2005.

[43] T. Friedli, J. W. Kolar, J. Rodriguez, and P. W. Wheeler, "Comparative Evaluation of Three-Phase AC-AC Matrix Converter and Voltage DC-Link Back-to-Back Converter Systems," Industrial Electronics, IEEE Transactions on, vol. 59, pp. 4487-4510, 2012.

[44] Gecko-SimulationsAG. GeckoCIRCUITS. Available: http://www.gecko-simulations.com

[45] L. Empringham, J. W. Kolar, J. Rodriguez, P. W. Wheeler, and J. C. Clare, "Technological Issues and Industrial Application of Matrix Converters: A Review," Industrial Electronics, IEEE Transactions on, vol. 60, pp. 4260-4271, 2013. 